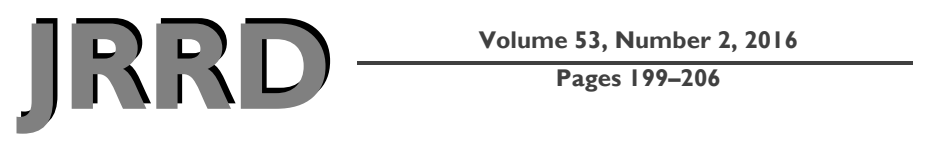

\title{
Prediction of oxygen uptake during walking in ambulatory persons with multiple sclerosis
}

\author{
Stamatis Agiovlasitis, PhD; ${ }^{{ }^{*}}$ Brian M. Sandroff, $\mathbf{M S} ;^{2}$ Robert W. Motl, $\mathbf{P h D}^{\mathbf{2}}$ \\ ${ }^{1}$ Department of Kinesiology, Mississippi State University, Mississippi State, MS; ${ }^{2}$ Department of Kinesiology and \\ Community Health, University of Illinois at Urbana-Champaign, Urbana, IL
}

\begin{abstract}
People with multiple sclerosis (MS) have an increased rate of gross oxygen uptake (gross- $\mathrm{VO}_{2}$ ) during treadmill walking, and their gross- $\mathrm{VO}_{2}$ may further vary with walking impairment. This study attempted to develop an equation for predicting gross- $\mathrm{VO}_{2}$ from walking speed and an index of walking impairment in persons with MS and examine its accuracy. Gross- $\mathrm{VO}_{2}$ was measured with open-circuit spirometry in 43 persons with MS ( $47+/-9 \mathrm{yr}$; 38 women) during five treadmill walking trials, each lasting 6 min, at 2.0, 2.5, 3.0, 3.5, and $4.0 \mathrm{mph}(0.89,1.12,1.34,1.56$, and $1.79 \mathrm{~m} / \mathrm{s})$. The $12-$ Item Multiple Sclerosis Walking Scale (MSWS-12) and the single-item Patient Determined Disease Steps scale (PDDS) provided indices of walking impairment. Multilevel modeling with random intercepts and slopes showed significant effects of speed and MSWS-12 on gross- $\mathrm{VO}_{2}\left(p</=0.014 ; R^{2}=\right.$ 0.70 ). PDDS was not a significant predictor. Gross- $-\mathrm{VO}_{2}$ estimated by the regression equation did not differ from actual gross- $\mathrm{VO}_{2}$ across speeds. Mean absolute prediction error across speeds was $9.1 \%$. The Bland-Altman plot indicated zero mean difference between actual and predicted gross- $\mathrm{VO}_{2}$ with modest 95\% confidence intervals. Therefore, speed and MSWS-12 score are jointly highly predictive of gross- $\mathrm{VO}_{2}$ during treadmill walking in persons with MS.
\end{abstract}

Key words: ambulation, disability, energy expenditure, exercise, gait, impairment, neuropathy, physical activity, regression equation, rehabilitation.

\section{INTRODUCTION}

Multiple sclerosis (MS) is an immune-mediated, inflammatory disease that damages neurons of the central nervous system and slows transmission of neural impulses in the brain, optic nerves, and spinal cord [1]. Symptoms of MS vary widely, but often include fatigue, depression, cognitive dysfunction, and mobility problems [2]. Walking ability, in particular, is commonly impaired among persons with MS, even those in the early course of the disease [3]. Further, persons with MS have lower physical activity and physical fitness levels than persons without MS [4-6]. Exercise training increases cardiovascular

\footnotetext{
Abbreviations: ACSM = American College of Sports Medicine, $\mathrm{BMI}=$ body mass index, gross- $\mathrm{VO}_{2}=$ rate of gross oxygen uptake, $\mathrm{MS}=$ multiple sclerosis, MSWS-12 $=12$-Item Multiple Sclerosis Walking Scale, PAR-Q = Physical Activity Readiness Questionnaire, PDDS = Patient Determined Disease Steps (scale).

*Address all correspondence to Stamatis Agiovlasitis, PhD; Department of Kinesiology, Mississippi State University, 233 McCarthy Gym, PO Box 6186, Mississippi State, MS 39762; 662-325-4772; fax: 662-325-4525.

Email: sagiovlasitis@colled.msstate.edu http://dx.doi.org/10.1682/JRRD.2014.12.0307
} 
and muscular fitness and may favorably affect fatigue, depression, mobility, and health-related quality of life in persons with MS [5,7]. Consequently, exercise training is a component of prescriptive care for patients with MS $[5,8]$.

Exercise programs for persons with MS must be carefully designed to maximize the associated benefits. In particular, rehabilitation professionals must ensure that persons with MS reach appropriate exercise intensities, especially during periods of exacerbation of symptoms $[5,8]$. Appropriate exercise intensities can be chosen by estimating the rate of gross oxygen uptake (gross- $\mathrm{VO}_{2}$; a measure of energy expenditure that includes resting metabolic rate) at a given workload along with assessment of aerobic fitness. During walking, gross- $\mathrm{VO}_{2}$ varies as a function of speed [8-9]; thus, rehabilitation professionals use equations estimating gross- $\mathrm{VO}_{2}$ from walking speed in determining the intensity of exercise. One such equation is that endorsed by the American College of Sports Medicine (ACSM), whereby gross- $\mathrm{VO}_{2}=3.5+[0.1 \times$ speed $\left.\left(\mathrm{m} \cdot \mathrm{min}^{-1}\right)\right]+[1.8 \times$ speed $\times$ percent grade (as fraction)] [8]. Such equations, however, have been developed in nondisabled people and underestimate the gross- $\mathrm{VO}_{2}$ in persons with MS [10]. Persons with MS have higher energy expenditure during walking than persons without MS [11-12], likely because of spasticity [13], altered gait patterns [14], and metabolic factors [15]. Such observations underscore the need for developing a formula specifically for persons with MS.

Gross- $\mathrm{VO}_{2}$ during walking varies between people with MS because of high interindividual variability in symptoms and mobility difficulties [16]. Therefore, a formula with only speed as the predictor might not effectively account for individual responses of gross- $\mathrm{VO}_{2}$ to speed in persons with MS. Seemingly, the different responses between people with MS could be captured by an index of ambulation difficulty, given that this is a factor that increases energy expenditure during walking [17]. Two indices that might be useful are provided by the 12-item Multiple Sclerosis Walking Scale (MSWS12) and the Patient Determined Disease Steps scale (PDDS). The MSWS-12 includes 12 patient-rated items that assess the multifactorial effect of MS on walking [18]. The PDDS consists of a single item for measuring self-reported functional impairment, with particular focus on ambulation [19-20]. MSWS-12 and PDDS scores have been positively associated with the energetic cost of walking in persons with MS [21-22]. Both of these scales provide easily derived measures of walking impairment that could improve the accuracy of predicting gross- $\mathrm{VO}_{2}$ during walking in persons with MS. More accurate prediction of gross- $\mathrm{VO}_{2}$ may allow exercise professionals to design safer and more effective walking programs for managing symptoms and improving health in persons with MS.

The purpose of this study was to develop an equation for predicting gross- $\mathrm{VO}_{2}$ during treadmill walking from speed and either the MSWS-12 or PDDS in persons with MS and to evaluate its predictability. We hypothesized that speed and MSWS-12 as well as PDDS would be significant predictors of gross- $\mathrm{VO}_{2}$.

\section{METHODS}

\section{Participants}

We recruited participants for this study through direct contact with support groups of a Midwestern chapter of the National MS Society. Participants with MS resided within an approximately 90 min drive of our campus. Inclusion criteria for participating in the study were (1) having a clinically definite diagnosis of MS, (2) being relapse-free for $30 \mathrm{~d}$ before testing, (3) being ambulatory without an assistive device, (4) being 18-64 yr old, (5) having the ability to read 14-point font, (6) being comfortable wearing the open-circuit spirometer (described in a subsequent section) during walking on a treadmill, and (7) not having risk factors for exercise testing based on the Physical Activity Readiness Questionnaire (PAR-Q). After screening 69 persons with MS, we enrolled 43 as participants in this study. The remaining 26 participants were excluded based on one or more affirmatives on the PAR-Q (i.e., risk factors for exercise testing).

\section{Protocol}

The protocol for this study was approved by a University of Illinois at Urbana-Champaign Institutional Review Board. All participants provided written informed consent. Participants attended two laboratory sessions separated by $7 \mathrm{~d}$. During the first testing session, participants completed demographic and physical activity questionnaires as well as the PDDS and MSWS-12. We then measured each participant's height and weight (in light clothing without shoes) using a scale-stadiometer unit (model 3P7044, Detecto; Webb City, Missouri). Finally, participants were familiarized with the protocol. 
Familiarization involved walking on a treadmill for 5-10 min while wearing the open-circuit spirometry system across a range of speeds. We did not collect oxygen uptake data during familiarization. This session allowed for determination of the appropriate range of speeds for the second session for each participant. That is, we identified the speed, if any, at which participants reported difficulty or discomfort with walking, and this speed represented an upward limit for the subsequent testing session.

Participants returned to the laboratory $7 \mathrm{~d}$ later to complete the testing session for measurement of gross$\mathrm{VO}_{2}$. Participants did not have food and caffeine for at least $3 \mathrm{~h}$ and did not exercise for at least $24 \mathrm{~h}$ before testing. Testing was conducted in a noise-attenuated and thermoneutral $\left(21^{\circ} \mathrm{C}\right)$ laboratory. Participants were fitted with the open-circuit spirometry system and sat quietly for $5 \mathrm{~min}$ to generate an estimate of resting oxygen uptake-we used this value only to ensure that participants were adequately rested between the trials described later. Participants then completed between two and five walking trials on a treadmill (Trackmaster, model TMX425C, Full Vision Inc; Newton, Kansas). We confirmed accuracy of the treadmill speed by measuring belt length and time for 25 revolutions of the belt. We also verified the treadmill grade $(0 \%)$ using a digital inclinometer (Beall Tilt Box, The Beall Tool Company; Newark, Ohio). The walking trials were each $6 \mathrm{~min}$ in duration, and there were $6 \mathrm{~min}$ of seated rest between trials, thereby allowing oxygen uptake to approach resting values. The five possible walking speeds were 2.0, 2.5, 3.0, 3.5 , and $4.0 \mathrm{mph}\left(0.89,1.12,1.34,1.56\right.$, and $\left.1.79 \mathrm{~m} \cdot \mathrm{s}^{-1}\right)$ (i.e., slow through fast walking). As mentioned previously, the number of trials to be completed per participant was determined during the first session based on reported difficulty or discomfort with walking. All 43 participants with MS completed the walking trials at 2.0 and $2.5 \mathrm{mph}$, whereas 35, 30, and 23 participants completed the trials at 3.0, 3.5, and $4.0 \mathrm{mph}$, respectively. The trials were conducted in a randomized order.

\section{Rate of Oxygen Uptake}

We measured gross- $\mathrm{VO}_{2}$ with an open-circuit spirometry system (TrueOne, Parvo Medics; Sandy, Utah) with a 2-way nonrebreathable valve (model 2700B, Hans Rudolph; Kansas City, Missouri). We calibrated the $\mathrm{O}_{2}$ and $\mathrm{CO}_{2}$ analyzers against room air and gases of known concentrations. A $3 \mathrm{~L}$ syringe was used to calibrate the flow meter (Hans Rudolph). We determined steady-state gross- $\mathrm{VO}_{2}$ in milliliters per kilogram per minute as the average over the last $3 \mathrm{~min}$ of the resting and walking trials.

\section{Walking Impairment}

The MSWS-12 and the PDDS were used as selfreport measures of walking impairment. The MSWS-12 provides a valid and reliable patient-rated measure of the effect of MS on walking [18,23-24]. The MSWS-12 has 12 items that are rated on a scale ranging between 1 ("Not at all”) and 5 (“Extremely"). The total MSWS-12 score is between 0 and 100 and is calculated by first adding the individual item scores, subtracting 12 (the minimum possible score), dividing by 48 (the maximal score), and then multiplying the result by 100 . The PDDS is an inexpensive surrogate for the Expanded Disability Status Scale for evaluating disability status and disease progression in persons with MS and has strong validity evidence [19-20,25]. The PDDS consists of a single item for assessing self-reported disability status on an ordinal scale, ranging from 0 (normal) through 8 (bedridden).

\section{Data Analyses}

Statistical analyses were performed with SPSS 21.0 (IBM; Armonk, New York). We analyzed the relationship between gross- $\mathrm{VO}_{2}$ and walking speed with multilevel modeling - a type of regression that accounts for nesting of observations within participants. The dependent variable was the gross- $\mathrm{VO}_{2}$ during walking. We modeled speed and either the MSWS-12 or the PDDS score as fixed effects. Additional factors considered as fixed effects were age, sex, MS type, and body mass index (BMI). The intercepts and slopes of the gross- $-\mathrm{VO}_{2}$ to speed relationship across participants were considered as possible random effects. Inclusion of individual parameters into the model was evaluated based on the difference in -2 log-likelihood between models against a chi-square distribution with 1 degree of freedom. We used the regression equation developed by multilevel modeling to predict each participant's gross- $\mathrm{VO}_{2}$ during each walking trial. In addition, we used paired samples $t$-tests to evaluate the difference between actual gross- $\mathrm{VO}_{2}$ and gross$\mathrm{VO}_{2}$ predicted by the regression equation across speeds for each group. Finally, we evaluated the agreement between actual and predicted gross- $\mathrm{VO}_{2}$ with BlandAltman plots [26] and with the absolute percent error, which was determined as 1 [(actual $\mathrm{VO}_{2}$ - predicted $\mathrm{VO}_{2}$ ) / actual $\left.\mathrm{VO}_{2}\right] \times 100 \mid$. The alpha level was 0.05 . 


\section{RESULTS}

\section{Participant Characteristics}

The sample consisted of 38 women and 5 men. The mean \pm standard deviation age of participants was $47 \pm$ $9 \mathrm{yr}$, height was $168.0 \pm 8.3 \mathrm{~cm}$, weight was $75.5 \pm$ $19.5 \mathrm{~kg}$, and BMI was $26.8 \pm 6.9 \mathrm{~kg} \cdot \mathrm{m}^{-2}$. Participants reported performing $30 \mathrm{~min}$ of moderate-to-vigorous physical activity on $3.4 \pm 2.1 \mathrm{~d} / \mathrm{wk}$. This sample, overall, had seemingly higher physical activity levels than typically reported in people with MS [4]; this might be explained by the nature of the research (i.e., walking on a treadmill across a variety of speeds) and the inclusion criteria based on ambulation and the PAR-Q (i.e., no affirmative answers). Forty persons had relapsing-remitting MS, two persons had secondary-progressive MS, and one person had primary progressive MS. Mean duration of MS was $10.7 \pm 7.8 \mathrm{yr}$. The mean MSWS-12 score was $22.5 \pm 20.4$ (range: 0.0-66.7), indicating that walking impairment among the present participants was minimal overall, but with large range. The median PDDS score was 1 , with a range of $0-5$; this also indicated minimal disability overall (i.e., some noticeable but minor symptoms from MS with minimal effect on lifestyle), but again there was a range of disability. The mean gross$\mathrm{VO}_{2}$ during walking at 2.0, 2.5, 3.0, 3.5, and $4.0 \mathrm{mph}$ was $10.8 \pm 1.4,12.3 \pm 1.7,13.7 \pm 1.5,15.7 \pm 1.3$, and $17.9 \pm$ $1.7 \mathrm{~mL} \cdot \mathrm{kg}^{-1} \cdot \mathrm{min}^{-1}$, respectively.

\section{Prediction of Oxygen Uptake}

The multilevel model indicated that the relationship between gross- $\mathrm{VO}_{2}$ and walking speed varied significantly in intercepts and slopes across participants $(p<$ $0.01)$. Speed and MSWS-12 score significantly predicted gross- $-\mathrm{VO}_{2}\left(p \leq 0.014 ; R^{2}=0.70\right.$; Table and Figure 1). Age, sex, MS type, and BMI did not contribute significantly to the regression. In the model with speed and PDDS score, only speed was a significant predictor of gross- $\mathrm{VO}_{2}(p<0.001)$; PDDS score was not a significant predictor $(p=0.08)$. Thus, we limited further analyses to the equation with speed and MSWS-12 score as predictors. The final prediction equation was-

$$
\begin{gathered}
\text { Gross- }-\mathrm{VO}_{2}\left(\mathrm{~mL} \cdot \mathrm{kg}^{-1} \cdot \mathrm{min}^{-1}\right)=2.804+3.602 \times \text { walking } \\
\text { speed }(\mathrm{mph})+0.026 \times \text { MSWS-12 }
\end{gathered}
$$

Actual gross- $\mathrm{VO}_{2}$ and predicted gross- $\mathrm{VO}_{2}$ estimated by the presently developed regression equation did
Table.

Estimates of fixed effects in multilevel model predicting rate of gross oxygen uptake (in milliliters per kilogram per minute) during treadmill walking in persons with multiple sclerosis.

\begin{tabular}{lcc}
\hline \multicolumn{1}{c}{ Variable } & $\boldsymbol{b}$ & SE \\
\hline Intercept $^{*}$ & 2.804 & 0.508 \\
Walking Speed (mph) $^{*}$ & 3.602 & 0.140 \\
MSWS-12 $^{*}$ & 0.026 & 0.010 \\
\hline
\end{tabular}

${ }^{*} p \leq 0.014$.
$b=$ unstandardized coefficient, MSWS-12 = 12-Item Multiple Sclerosis Walk-
ing Scale, SE = standard error.

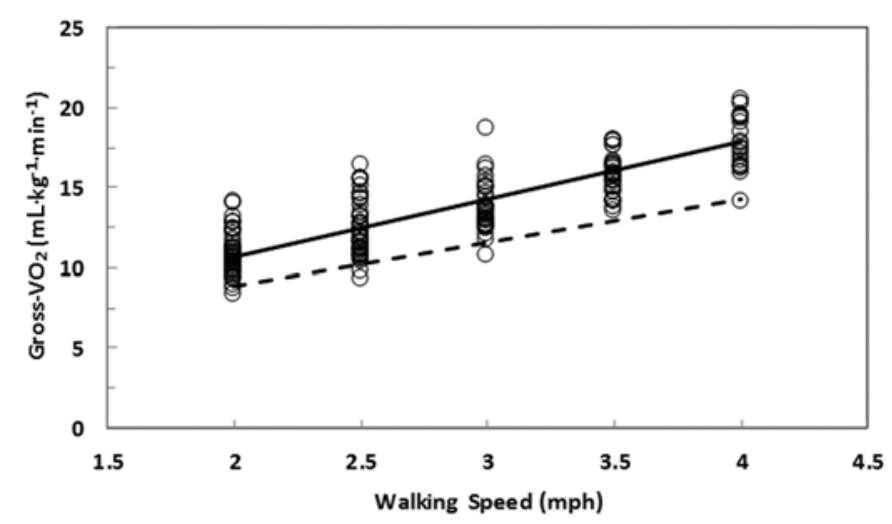

Figure 1.

Rate of gross oxygen uptake (gross- $\mathrm{VO}_{2}$ ) as a function of walking speed in persons with multiple sclerosis. Solid line shows mean regression using coefficients of multilevel model described in Table. Dotted line shows gross $-\mathrm{VO}_{2}$ estimated by American College of Sports Medicine prediction equation across speeds.

not differ significantly at any of the speeds $(p \geq 0.095)$. Mean absolute error across speeds was relatively small at 9.1 percent. The Bland-Altman plot indicated zero mean difference between actual and predicted gross $-\mathrm{VO}_{2}$ with modest 95 percent confidence intervals (Figure 2).

\section{DISCUSSION}

The purpose of this study was to examine whether gross- $\mathrm{VO}_{2}$ during treadmill walking can be predicted from speed and an indicator of ambulation problems in persons with MS. The primary findings were that speed and MSWS-12 score were significant predictors of gross- $\mathrm{VO}_{2}$ and that the prediction equation developed had relatively small error. In contrast, PDDS score was not a significant 


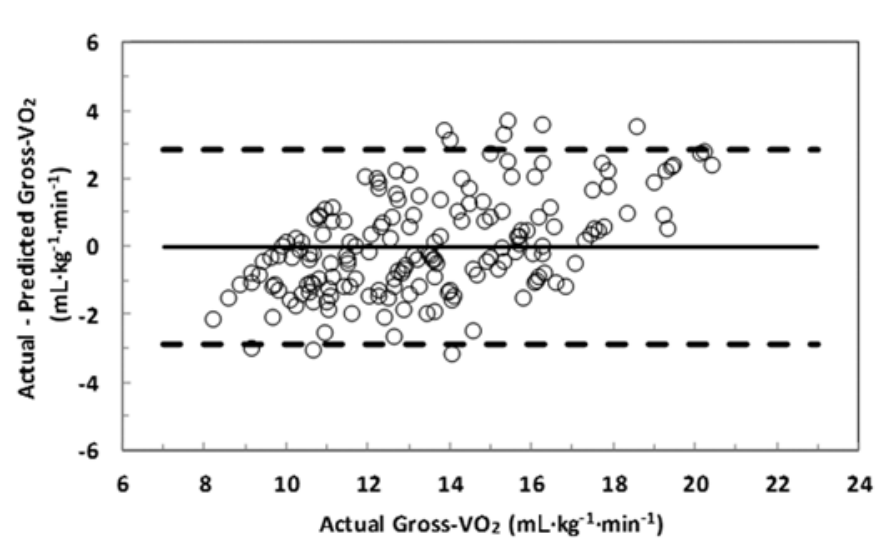

Figure 2.

Bland-Altman plot of the difference between the actual rate of gross oxygen uptake (gross- $\mathrm{VO}_{2}$ ) and gross $-\mathrm{VO}_{2}$ predicted by multilevel modeling regression equation as a function of actual gross- $\mathrm{VO}_{2}$ in persons with multiple sclerosis. Solid and dotted lines show mean and 95 percent limits of agreement, respectively.

predictor of gross- $\mathrm{VO}_{2}$. These results have clear implications for the prescription of exercise intensity in clinical research and practice involving persons with MS.

We found that, apart from speed, the MSWS-12 total score was predictive of gross- $\mathrm{VO}_{2}$ during walking in persons with MS. This is consistent with previous research indicating that the MSWS-12 score is associated with the oxygen cost per unit distance in persons with MS [21]. Furthermore, MSWS-12 scores have been positively associated with the duration of the double-support phase of walking at preferred speeds [27]—a factor that increases energy expenditure [28]. The effect of the MSWS-12 score on gross $-\mathrm{VO}_{2}$ at a given speed can be quantified as the product of the respective beta coefficient and the mean MSWS-12 score of the present participants (i.e., $0.026 \times 22.5=0.59 \mathrm{~mL} \cdot \mathrm{kg}^{-1} \cdot \mathrm{min}^{-1}$ ). Although this effect appears small, its magnitude may be practically significant for persons with higher MSWS-12 scores (maximum score in the present study was 66.7, in which case the effect is $1.73 \mathrm{~mL} \cdot \mathrm{kg}^{-1} \cdot \mathrm{min}^{-1}$ ). Furthermore, this effect carries theoretical significance because it shows that the response of gross- $\mathrm{VO}_{2}$ to walking speed varies between persons with MS based on their walking limitations, and this variance can be captured-at least partially_by the MSWS-12. This easily administered scale evaluates the perceived severity of walking impairment and has moderate to strong associations with spatiotemporal gait characteristics and walking performance
[27]. In contrast, the PDDS score was not a significant predictor of gross- $\mathrm{VO}_{2}$, suggesting that it shared less variance with gross- $\mathrm{VO}_{2}$ than the MSWS-12 score in the present participants. In support of this argument, PDDS scores have somewhat lower correlation with the oxygen cost per unit distance than MSWS-12 scores [21-22]. PDDS provides a single categorical rating of disease progression [19] and may be less sensitive or specific than the MSWS-12 scale in discriminating walking difficulties between persons with MS with minimal limitations such as the present participants. From a theoretical standpoint, our results suggest that including a measure of walking impairment improves predictability of gross$\mathrm{VO}_{2}$ during walking in persons with MS.

The predictability of the presently developed formula is promising. Mean absolute percent error was relatively small-smaller than that reported in other populations [29]. Furthermore, the Bland-Altman plots showed zero mean error of agreement, suggesting that the present equation does not have systematic error across all speeds combined. Furthermore, the 95 percent limits of agreement in the Bland-Altman plots were similar to those found in nondisabled persons and persons with other disabilities [29], but did indicate some variation in individual predictability. Although the reasons for this effect cannot be determined based on the present data, the reasons may relate to the diverse effects of MS between people [2] - ones that cannot be captured fully by the MSWS-12. In fact, the present model explained 70 percent of the variance in gross- $\mathrm{VO}_{2}$; thus, the remaining 30 percent of the variance is explained by factors other than speed and MSWS-12 score, and our analyses indicated that these are not MS type, age, sex, or BMI. MSWS-12 provides a valid and reliable measure of walking ability in people with MS [18,23-24], but it may still not capture fine differences between people in diseaserelated alterations that may decrease energetic efficiency during aerobic activity. These could potentially include increased gait variability [14], spasticity [13], and thermoregulation difficulties [5], as well as decreased oxidative enzyme activity and number and size of oxidative muscle fibers [15]. Nonetheless, the present model with speed and MSWS-12 score as predictors accounted for a large proportion of the variance in gross- $\mathrm{VO}_{2}$ and showed a high degree of accuracy.

The prediction formula developed herein along with the results of aerobic fitness assessment may aid in designing exercise programs that involve walking for 
improving health and other rehabilitation outcomes in persons with MS. Let us assume the hypothetical case of a woman with an MSWS-12 score of 50 who reports high fatigability and is deconditioned as indicated by a peak oxygen uptake of $25 \mathrm{~mL} \cdot \mathrm{kg}^{-1} \cdot \mathrm{min}^{-1}$ (such values are typically reported in persons with MS [30]). For the initial stage of exercise training, a rehabilitation professional may_reasonably_prescribe treadmill walking at 50 percent of peak $\mathrm{VO}_{2}$ [8]. In this example, the target level of gross- $\mathrm{VO}_{2}$ is $12.5 \mathrm{~mL} \cdot \mathrm{kg}^{-1} \cdot \mathrm{min}^{-1}$. As calculated by the present equation, this exercise intensity may be achieved by having this woman walk on a treadmill at $2.3 \mathrm{mph}$. In contrast, using the formula endorsed by the ACSM, one would mistakenly determine that this woman should exercise at $3.4 \mathrm{mph}$. At that speed, our formula predicts $16.4 \mathrm{~mL} \cdot \mathrm{kg}^{-1} \cdot \mathrm{min}^{-1}$ or 65.4 percent of her peak $\mathrm{VO}_{2}-$ this intensity may be unnecessarily large for the initial stage of the exercise program, cause needless fatigue, and discourage the participant. As previous research has found, the ACSM formula underestimates gross- $\mathrm{VO}_{2}$ in persons with MS because their net oxygen uptake per meter is higher than that assumed by that equation [10]. If a purpose of the exercise program is weight control, rehabilitation specialists could use the present formula to more accurately estimate the total caloric output for the walking bout. This can be achieved by first converting the predicted gross- $\mathrm{VO}_{2}$ from milliliters per kilogram per minute to liters per minute, multiplying by $4.9 \mathrm{kcal} \cdot \mathrm{L}^{-1}$ [8-9], and then multiplying by the bout duration in minutes. For all purposes, the rehabilitation professional needs to be aware that-as for all prediction equationsthe present formula has some error; thus, target walking intensities should be chosen cautiously and adjusted based on individual responses and perceptions. Nevertheless, a formula that is developed specifically for persons with MS is likely to be more appropriate than one developed for persons without MS. Well-designed exercise programs may promote health and improve adherence to physical activity in persons with MS.

The following limitations should be considered. First, the present prediction equation was generated with data from treadmill walking and may not be applicable to overground walking. Second, the present participants reported primarily relapsing-remitting MS, relatively mild mobility problems, and higher than expected physical activity levels; thus, our results may not generalize to persons with MS in different disability stages and with lower levels of physical activity. Third, our sample may not have been large enough to allow for the detection of the effect of PDDS score. Fourth, we tested more women than men; however, it should be noted that MS is more prevalent among women [31]. Finally, some participants did not undertake the faster walking trials; however, it should be considered that missing data do not present a problem in multilevel modeling.

\section{CONCLUSIONS}

In conclusion, speed and MSWS-12 score predict gross- $\mathrm{VO}_{2}$ during treadmill walking in persons with MS. The prediction equation developed had relatively small error. Rehabilitation professionals—clinicians and researchers-should refrain from using equations that have not been developed in persons with MS. Rehabilitation professionals could cautiously use the presently developed formula when designing walking programs for persons with MS. Well-designed programs may encourage persons with MS to engage in physical activity and experience its benefits on health.

\section{ACKNOWLEDGMENTS}

\section{Author Contributions:}

Study concept and design: S. Agiovlasitis, R. W. Motl, B. M. Sandroff.

Data collection: B. M. Sandroff, R. W. Motl.

Data analyses: S. Agiovlasitis, R. W. Motl, B. M. Sandroff.

Drafting of manuscript: S. Agiovlasitis, R. W. Motl, B. M. Sandroff.

Financial Disclosures: The authors have declared that no competing interests exist.

Funding: This material was based on work supported by a gift from the Consortium of Multiple Sclerosis Centers.

Additional Contributions: Brian M. Sandroff has completed his doctorate and is now with the Kessler Foundation, West Orange, New Jersey. Institutional Review: The study was approved by a University of Illinois at Urbana-Champaign Institutional Review Board, and written informed consent was obtained from all participants.

Participant Follow-up: The authors do not plan to inform participants regarding publication of this study.

\section{REFERENCES}

1. Trapp BD, Nave KA. Multiple sclerosis: An immune or neurodegenerative disorder? Annu Rev Neurosci. 2008;31: 247-69. [PMID:18558855] http://dx.doi.org/10.1146/annurev.neuro.30.051606.094313 
2. Lublin FD, Reingold SC; National Multiple Sclerosis Society (USA) Advisory Committee on Clinical Trials of New Agents in Multiple Sclerosis. Defining the clinical course of multiple sclerosis: Results of an international survey. Neurology. 1996;46(4):907-11. [PMID:8780061] http://dx.doi.org/10.1212/WNL.46.4.907

3. Larocca NG. Impact of walking impairment in multiple sclerosis: Perspectives of patients and care partners. Patient. 2011;4(3):189-201. [PMID:21766914] http://dx.doi.org/10.2165/11591150-000000000-00000

4. Motl RW, McAuley E, Snook EM. Physical activity and multiple sclerosis: A meta-analysis. Mult Scler. 2005; 11(4):459-63. [PMID:16042230] http://dx.doi.org/10.1191/1352458505ms1188oa

5. White LJ, Dressendorfer RH. Exercise and multiple sclerosis. Sports Med. 2004;34(15):1077-1100. [PMID:15575796] http://dx.doi.org/10.2165/00007256-200434150-00005

6. Guerra E, di Cagno A, Mancini P, Sperandii F, Quaranta F, Ciminelli E, Fagnani F, Giombini A, Pigozzi F. Physical fitness assessment in multiple sclerosis patients: A controlled study. Res Dev Disabil. 2014;35(10):2527-33. [PMID:25000308] http://dx.doi.org/10.1016/j.ridd.2014.06.013

7. Latimer-Cheung AE, Pilutti LA, Hicks AL, Martin Ginis KA, Fenuta AM, MacKibbon KA, Motl RW. Effects of exercise training on fitness, mobility, fatigue, and healthrelated quality of life among adults with multiple sclerosis: A systematic review to inform guideline development. Arch Phys Med Rehabil. 2013;94(9):1800-1828.

[PMID:23669008] http://dx.doi.org/10.1016/j.apmr.2013.04.020

8. American College of Sports Medicine. ACSM's guidelines for exercise testing and prescription. 9th ed. Baltimore (MD): Lippincott Williams \& Wilkins; 2014.

9. McArdle WD, Katch FI, Katch VL. Exercise physiology: Energy, nutrition, and human performance. 8th ed. Baltimore (MD): Lippincott Williams \& Wilkins; 2015.

10. Agiovlasitis S, Motl RW, Fernhall B. Prediction of oxygen uptake during level treadmill walking in people with multiple sclerosis. J Rehabil Med. 2010;42(7):650-55.

[PMID:20603695]

http://dx.doi.org/10.2340/16501977-0570

11. Motl RW, Snook EM, Agiovlasitis S, Suh Y. Calibration of accelerometer output for ambulatory adults with multiple sclerosis. Arch Phys Med Rehabil. 2009;90(10):1778-84. [PMID:19801071] http://dx.doi.org/10.1016/j.apmr.2009.03.020

12. Olgiati R, Jacquet J, Di Prampero PE. Energy cost of walking and exertional dyspnea in multiple sclerosis. Am Rev Respir Dis. 1986;134(5):1005-10. [PMID:3777662] http://dx.doi.org/10.1164/arrd.1986.134.5.1005
13. Olgiati R, Burgunder JM, Mumenthaler M. Increased energy cost of walking in multiple sclerosis: Effect of spasticity, ataxia, and weakness. Arch Phys Med Rehabil. 1988;69(10):846-49. [PMID:3178452]

14. Sosnoff JJ, Sandroff BM, Motl RW. Quantifying gait abnormalities in persons with multiple sclerosis with minimal disability. Gait Posture. 2012;36(1):154-56.

[PMID:22424761]

http://dx.doi.org/10.1016/j.gaitpost.2011.11.027

15. Kent-Braun JA, Ng AV, Castro M, Weiner MW, Gelinas D, Dudley GA, Miller RG. Strength, skeletal muscle composition, and enzyme activity in multiple sclerosis. J Appl Physiol. 1997;83(6):1998-2004. [PMID:9390973]

16. Motl RW, Suh Y, Balantrapu S, Sandroff BM, Sosnoff JJ, Pula J, Goldman MD, Fernhall B. Evidence for the different physiological significance of the 6- and 2-minute walk tests in multiple sclerosis. BMC Neurol. 2012;12:6.

[PMID:22380843]

http://dx.doi.org/10.1186/1471-2377-12-6

17. Waters RL, Mulroy S. The energy expenditure of normal and pathologic gait. Gait Posture. 1999;9(3):207-31. [PMID:10575082]

http://dx.doi.org/10.1016/S0966-6362(99)00009-0

18. Hobart JC, Riazi A, Lamping DL, Fitzpatrick R, Thompson AJ. Measuring the impact of MS on walking ability: The 12-Item MS Walking Scale (MSWS-12). Neurology. 2003;60(1):31-36. [PMID:12525714] http://dx.doi.org/10.1212/WNL.60.1.31

19. Hohol MJ, Orav EJ, Weiner HL. Disease steps in multiple sclerosis: A simple approach to evaluate disease progression. Neurology. 1995;45(2):251-55. [PMID:7854521] http://dx.doi.org/10.1212/WNL.45.2.251

20. Hohol MJ, Orav EJ, Weiner HL. Disease steps in multiple sclerosis: A longitudinal study comparing disease steps and EDSS to evaluate disease progression. Mult Scler. 1999;5(5):349-54. [PMID:10516779] http://dx.doi.org/10.1177/135245859900500508

21. Motl RW, Dlugonski D, Suh Y, Weikert M, Agiovlasitis S, Fernhall B, Goldman M. Multiple Sclerosis Walking Scale12 and oxygen cost of walking. Gait Posture. 2010;31(4):506-10. [PMID:20226676] http://dx.doi.org/10.1016/j.gaitpost.2010.02.011

22. Motl RW, Suh Y, Dlugonski D, Weikert M, Agiovlasitis S, Fernhall B, Goldman M. Oxygen cost of treadmill and over-ground walking in mildly disabled persons with multiple sclerosis. Neurol Sci. 2011;32(2):255-62.

[PMID:20798968]

http://dx.doi.org/10.1007/s10072-010-0396-0

23. Learmonth YC, Dlugonski DD, Pilutti LA, Sandroff BM, Motl RW. The reliability, precision and clinically meaningful change of walking assessments in multiple sclerosis. 
JRRD, Volume 53, Number 2, 2016

Mult Scler. 2013;19(13):1784-91. [PMID:23587605]

http://dx.doi.org/10.1177/1352458513483890

24. McGuigan C, Hutchinson M. Confirming the validity and responsiveness of the Multiple Sclerosis Walking Scale-12 (MSWS-12). Neurology. 2004;62(11):2103-5. [PMID:15184625]

http://dx.doi.org/10.1212/01.WNL.0000127604.84575.0D

25. Learmonth YC, Motl RW, Sandroff BM, Pula JH, Cadavid D. Validation of Patient Determined Disease Steps (PDDS) scale scores in persons with multiple sclerosis. BMC Neurol. 2013;13(1):37. [PMID:23617555]

http://dx.doi.org/10.1186/1471-2377-13-37

26. Bland JM, Altman DG. Measuring agreement in method comparison studies. Stat Methods Med Res. 1999;8(2): 135-60. [PMID:10501650]

http://dx.doi.org/10.1191/096228099673819272

27. Pilutti LA, Dlugonski D, Sandroff BM, Suh Y, Pula JH, Sosnoff JJ, Motl RW. Further validation of Multiple Sclerosis Walking Scale-12 scores based on spatiotemporal gait parameters. Arch Phys Med Rehabil. 2013;94(3):575-78. [PMID:22960049] http://dx.doi.org/10.1016/j.apmr.2012.08.214

28. Kuo AD. The six determinants of gait and the inverted pendulum analogy: A dynamic walking perspective. Hum Mov Sci. 2007;26(4):617-56. [PMID:17617481]

http://dx.doi.org/10.1016/j.humov.2007.04.003

29. Agiovlasitis S, Motl RW, Ranadive SM, Fahs CA, Yan H, Echols GH, Rossow L, Fernhall B. Prediction of oxygen uptake during over-ground walking in people with and without Down syndrome. Eur J Appl Physiol. 2011;111(8):
1739-45. [PMID:21221988]

http://dx.doi.org/10.1007/s00421-010-1812-0

30. Motl RW, Fernhall B. Accurate prediction of cardiorespiratory fitness using cycle ergometry in minimally disabled persons with relapsing-remitting multiple sclerosis. Arch Phys Med Rehabil. 2012;93(3):490-95. [PMID:22225573] http://dx.doi.org/10.1016/j.apmr.2011.08.025

31. Noonan CW, Kathman SJ, White MC. Prevalence estimates for MS in the United States and evidence of an increasing trend for women. Neurology. 2002;58(1):136-38. [PMID:11781421]

http://dx.doi.org/10.1212/WNL.58.1.136

Submitted for publication December 10, 2014. Accepted in revised form July 6, 2015.

This article and any supplementary material should be cited as follows:

Agiovlasitis S, Sandroff BM, Motl RW. Prediction of oxygen uptake during walking in ambulatory persons with multiple sclerosis. J Rehabil Res Dev. 2016;53(2): 199-206.

http://dx.doi.org/10.1682/JRRD.2014.12.0307

ORCID: Stamatis Agiovlasitis, PhD: 0000-0003-2307219X

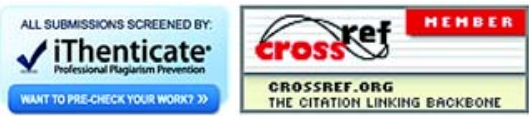

